\title{
GCU
}

Glasgow Caledonian

University

University for the Common Good

\section{Exploring purpose-designed audio-visual falls prevention messages on older people's capability and motivation to prevent falls}

de Jong, Lex D.; Lavender, Andrew P.; Wortham, Chris; Skelton, Dawn A.; Haines, Terry P.; Hill, Anne-Marie

Published in:

Health and Social Care in the Community

DOI:

10.1111/hsc. 12747

Publication date:

2019

Document Version

Author accepted manuscript

Link to publication in ResearchOnline

Citation for published version (Harvard):

de Jong, LD, Lavender, AP, Wortham, C, Skelton, DA, Haines, TP \& Hill, A-M 2019, 'Exploring purpose-

designed audio-visual falls prevention messages on older people's capability and motivation to prevent falls', Health and Social Care in the Community, vol. 27, no. 4, pp. e471-e482. https://doi.org/10.1111/hsc.12747

\section{General rights}

Copyright and moral rights for the publications made accessible in the public portal are retained by the authors and/or other copyright owners and it is a condition of accessing publications that users recognise and abide by the legal requirements associated with these rights.

Take down policy

If you believe that this document breaches copyright please view our takedown policy at https://edshare.gcu.ac.uk/id/eprint/5179 for details

of how to contact us. 


\section{Title}

Exploring Purpose-Designed Audiovisual Falls Prevention Messages on Older People's Capability and Motivation to Prevent Falls.

\section{Abstract}

The number of falls and fall-associated injury rates among older people continue to rise worldwide. Increased efforts to influence older people's falls prevention behaviour are needed. A two-phase exploratory community-based participatory study was conducted in (Blinded For Review). First, three prototype audiovisual (AV) falls prevention messages were designed collaboratively with six older people. Second, the messages' effect on communitydwelling older people's knowledge, awareness and motivation to take action regarding falls prevention was explored using focus groups. Data were analysed using thematic analysis to explore participants' responses to the messages. The participants' $(n=54)$ perspectives on the AV messages varied widely and stereotypes of aging appeared to influence these. The presented falls facts (including falls epidemiology statistics) increased some participants' falls risk awareness and falls prevention knowledge. Other participants felt ready-to-use falls prevention information was lacking. Some expressed positive emotions or a personal connection to the messages and suggested the messages helped reduce aging-related stigma. Strongly opposing viewpoints suggested that other participants identified implicit negative messages about aging, which reduced their motivation with the messages. Suggestions to improve the message persuasiveness included adding more drama and tailoring messages to appeal to multiple age groups. Overall, the AV falls prevention messages designed in collaboration with older people elicited a divergent range of positive and negative perspectives from their peers, which was conceptualised by the overarching theme "we all look at things different ways". Opinions differed regarding whether the messages would appeal to older people. Public campaigns targeting falls prevention should be designed and tailored towards older peoples' differing perspectives about aging. 
Keywords: Accidental falls, Community-based participatory research, Consumer health information, Health behaviour, Qualitative research.

\section{What is known about this topic}

- Falls are the leading cause of injury among older adults.

- Older people do not proactively access falls prevention information.

- A stronger population-based focus is required to raise older peoples' awareness, knowledge and motivation to take up falls prevention strategies in much larger numbers.

\section{What this paper adds}

- Audio-visual falls prevention messages designed in collaboration with a small group of community-dwelling older people elicited strong divergent positive and negative perspectives by their peers regarding the effect of the messages on falls prevention capability and motivation.

- Future population-level falls prevention campaigns should be designed and tailored towards older peoples' differing perspectives about aging.

\section{Introduction}

Falls are the leading cause of injury (Bergen, Stevens, \& Burns, 2016) among older adults, with falls causing over 27,000 deaths in one year alone in the United States (Ambrose, Paul, 
\& Hausdorff, 2013). Because falls pose a significant global problem, the World Health Organization has recommended a proactive and systematic approach to falls prevention policies and strategies which is tailored to target populations (World Health Organization, 2007).

There has been an increase in the number of falls prevention resources developed in the last decade such as national best practice guidelines (Australian Commission on Safety and Quality in Healthcare, 2009), national and international frameworks for falls prevention (Agency for Healthcare Research and Quality, 2017; World Health Organization, 2007), local multimedia campaigns (John-Leader et al., 2008), online falls prevention resources (Centers for Disease Control and Prevention, 2017) and locally run affordable exercise activities for falls prevention (Smith et al., 2018). Despite the availability of these resources and local opportunities, there continues to be an alarming increase in injuries due to falling. For example, in the United States the age-adjusted rate of fall-related injuries increased 4-5\% per year from 2004-2013 among older adults (Verma et al., 2016).

Older adults lack knowledge and motivation to effectively prevent falls (Franco et al., 2015; Haines, Day, Hill, Clemson, \& Finch, 2014; Khong, Bulsara, Hill, \& Hill, 2016). Knowledge and motivation are some of the important 'active ingredients' necessary for bringing about health behaviour change according to the Behaviour Change Wheel and Theoretical Domains Framework approach, a theoretical psychological model of behaviour change (Michie, Atkins, \& West, 2014). However, multiple studies have demonstrated that many older adults believe that falls prevention is not personally relevant to them (Dollard, Barton, Newbury, \& Turnbull, 2013), most often because they feel they are not at risk of falling (Khong et al., 2016). It has been suggested that these beliefs are associated with a perceived implication of dependency and incompetence (Clark et al., 2013; Gardiner et al., 2017). These beliefs may partly explain why older people, even when they are aware of fall prevention resources, do not use them (McMahon et al., 2018). A large national survey found that $63 \%$ of communitydwelling older people expressed no interest in participating in any of six proposed programme 
formats for managing concerns about falls (Dorresteijn, Zijlstra, Van Eijs, Vlaeyen, \& Kempen, 2012). Among the responders who reported concerns about falls, the interest to participate in at least one format was only $46 \%$. Findings like these emphasise the need for research focused on identifying obstacles that prevent older people from overcoming the gap between their belief and awareness about falls and their actual falls risk, which leads to underutilisation of appropriate resources. One such obstacle could be the lack of mass media campaigns with appropriate messaging (McMahon et al., 2018) or that such campaigns have not impacted on the broad population of older people, their families and communities. A recent survey conducted after an 18-month multi-media campaign aimed at reducing falls found that, although more than one-third of respondents recognised the campaign, only $25 \%$ sought more information about physical activity and only $22 \%$ had become more active as a result (John-Leader et al., 2008). This suggests that a stronger population-based focus is required to raise older peoples' awareness, knowledge and motivation to take up falls prevention strategies in much larger numbers.

Recently, a community World Café forum was conducted to gain older people's perspectives about how falls prevention messages could be effectively disseminated to promote engagement with the messages and enhance subsequent uptake of recommended falls prevention recommended strategies (Khong et al., 2016). Findings from this forum strongly suggested that older people were only seeking help after having fallen, meaning that falls prevention information was not accessed proactively. Forum participants further highlighted that while falls prevention messages should be disseminated by health professionals, they should also be taken to the broader community to raise knowledge and awareness about falls prevention. This concurs with qualitative findings that demonstrated that health professionals and caregivers tended not to initiate discussions about falls (Lee, McDermott, Hoffmann, \& Haines, 2013). Therefore, we explored how to create persuasive community falls prevention messages that were aimed at a broad target audience and could potentially direct older people 
and their families to available falls prevention resources before they fell. The purpose of this study was to design a series of audio-visual (AV) falls prevention messages in collaboration with community-dwelling older people and explore the messages' effect on older people's knowledge, awareness and motivation to take action regarding falls prevention.

\section{Methods}

\section{Design}

This was an exploratory qualitative study using a community-based participatory approach (Israel, Eng, Schulz, \& Parker, 2005) in two phases. Ethics approval for the study was granted by the (Blinded for Review) Human Research Ethics Office (approval number Blinded For Review).

\section{Phase I: Design of the AV falls prevention messages}

In phase one the researchers invited community members to form a community reference panel. A collaborative partnership was established to ensure that the content and design of the messages were relevant to, and reflected the needs of, older people of the local community while the researchers provided input regarding the evidence-based content of the messages. The research team advertised for this panel of local older people by using local network contacts. Six people (three men, three women, age range 65-79) joined the panel. They received an oral introduction to the background of the project and an oral summary of the evidence base regarding health promotion and falls prevention among older people. The consensus was that the presented falls facts (including falls epidemiology statistics) were compelling. Panel members further felt that it was important to develop messages that would positively influence older people's falls prevention knowledge, motivate and encourage them to take action to find out more about reducing their risk of falling and to engage in falls prevention activities. Panel members' consensus on what specific messages were to be conveyed were that falls can and will happen to anyone and that one should prepare oneself 
for preventing a fall by doing activities that are enjoyable. The messages should also be delivered with humor. A professional filmmaker translated the suggested messages and ideas into three separate storyboards, which were reviewed during the second panel meeting. Suggested amendments to the storyboards were subsequently incorporated by the filmmaker. Several panel members attended the subsequent filming sessions to provide immediate feedback to the director about how scenes should look. Subsequently, preliminary versions of the AV messages were shared with the panel members via a web link and each member was invited to provide feedback. Their feedback was used to edit the AV messages further. All panel members provided final approval for each message. Each of the prototype AV messages (which can be found here: https://doi.org/10.25917/5b3c2e51c22b3) focused on a different aspect of the falls prevention message.

\section{Phase II: Focus groups}

In phase two, community-dwelling older people were invited to attend focus groups to watch and provide feedback on the prototype AV messages. This approach was chosen to allow for discussions that could help to elicit and validate views and opinions of others (Davidson, Halcomb, \& Gholizadeh, 2013), whilst at the same time exploring a collective perspective on the messages, especially because falls can be considered a stigmatising topic for older adults (Hanson, Salmoni, \& Doyle, 2009).

\section{Sample size}

A purposeful sampling method was conducted to recruit a minimum of 50 participants for the focus groups, a number considered sufficient for providing rich and meaningful data about older people's perspectives on the prototype AV messages to the point of data saturation (Braun \& Clarke, 2013). The sampling frame sought a range of older people in terms of age and gender as the expectation was that men and women of different ages might think differently about the messages (Khong, Berlach, Hill, \& Hill, 2017; Stevens et al., 2012). 


\section{Participants}

Community-dwelling men and women over the age of 50 were recruited from urban and rural areas in (Blinded for Review) through advertising an e-flyer in newsletters of local organisations as well as by word-of-mouth using local network and health professional contacts. Participants were eligible for participation if they were living independently, were sufficiently mobile to attend a community focus group, had sufficient English language skills (self-assessed) to join in the focus group discussion and were able to provide written informed consent.

\section{Focus group procedure}

Each focus group was organised in the community and took place in a convenient and easily accessible room at the locations where participants had agreed to participate. The nature of the groups meant that most participants were acquainted with the others in their group. Each participant provided signed informed consent prior to the focus groups. Groups commenced with refreshments and a short introduction about the purpose of the study. Each of the three AV message was subsequently played on a large TV, followed by a discussion round. The discussion rounds were moderated by a male researcher (Blinded For Review) who conducted this research and who had two years of previous experience in moderating focus groups. All but the smallest focus groups were also observed by a second researcher (Blinded For Review) who had experience in qualitative research and in working with older people. The second researcher took notes and focused on the participant's non-verbal signs. The discussion guide was based on the COM-B (Capability, Opportunity, Motivation to undertake a health Behavior) framework (Michie, Atkins, \& West, 2014). This framework, which can be applied to people's behaviour necessary to do something about their falls risk, conceptualises that for any (change in) behaviour to occur the people concerned must have the capability (e.g. falls prevention knowledge-, awareness- and skills), opportunity (e.g. accessibility to and 
affordability of falls prevention programmes) and motivation (e.g. intentions and desires to take up falls prevention activities) to do it. The guide contained a set of semi-structured, openended questions and prompts asking participants about if and how the message influenced their falls prevention knowledge and understanding, their emotional reactions to the message and how their perceptions about the message influenced their intentions and motivation to undertake falls prevention action. After the group viewed and discussed each AV message, the moderator summarised the key responses and invited participants to provide any further input and feedback for member checking purposes. All audio recordings were fully transcribed verbatim and anonymised. Transcripts were not returned to participants for comments or corrections.

\section{Data analysis}

Data from focus group transcripts were thematically analysed, taking both a deductive and inductive approach (Braun \& Clarke, 2013). The deductive approach, which allowed for the testing of anticipated responses to the AV messages(s), was also based on the COM-B health behaviour change framework (Michie, Atkins, \& West, 2014). Out of the existing six model components, three (psychological capability-education; automatic motivation-persuasion; reflective motivation-persuasion) were derived from this framework in advance to inform the preliminary coding scheme. Firstly, anonymised focus group transcripts were read through by two researchers (Blinded For Review) several times to familiarise themselves with the data. Using Microsoft Excel, they then independently organised codes under one of the three main themes in a stepwise categorisation process. To illuminate potential blind spots in the analysis process, a third researcher (Blinded For Review) was then asked to independently code a sample of the data and to review the coding scheme. The three researchers discussed each step throughout the coding and identification of candidate themes until consensus was reached (Braun \& Clarke, 2013). An inductive approach was then taken which allowed for exploring unanticipated themes and these were organised using open coding and listing codes under 
higher order heading. Agreement on the final themes and all codes was sought from all authors. Representative verbatim quotations were selected to exemplify the formation of themes and subthemes (Polit \& Beck, 2014) and labeled to indicate gender (M, F), location (L1-6), which AV message the quote related to (AVm 1-3) or whether it was an overall comment.

\section{Findings}

\section{Focus groups}

Forty-five participants attended one of six 90-minute focus groups. Characteristics of the participants and participants per focus group location are presented in Table 1. All participants were 62 years or older, other than one participant who was 54 years old (age range 54-95 years).

$<$ Insert Table 1 about here $>$

Overall there were conflicting discussions within the different focus groups and the participant's responses demonstrated that the three AV messages inspired a divergent range of positive and negative perspectives. The overarching theme which conceptualised participants' responses to the AV messages was concisely captured by one of the participants saying: "we all look at things different ways." (F, L4, overall comment). It was apparent that participants' responses appeared to be elicited by factors intrinsic to themselves, as both within and between groups participants frequently shared opposing comments about the same aspect of the AV messages (see Table 2). This was exemplified by comments on the length of the AV messages where one participant stated that they were "the length it's got to be." (F, L1, overall comment) while another said "they should be a bit longer, ..." (F, L1, overall comment) 
$<$ Insert Table 2 about here $>$

$<$ Insert Figure 1 about here $>$

Two main deductive themes were developed (Fig 1). One identified participants' positive perspectives relating to the educating and persuasive nature of the AV messages. This main theme suggested that participants who interpreted the messages as positive had viewed them through a positive stereotype of aging 'lens'. Viewing messages through a negative stereotype of aging 'lens' was associated with the other main theme, reflecting that these participants' described negative perspectives about the messages. This group of participants stated that they found the AV messages non-educating and non-persuasive. One main inductive theme was also identified which described some participants' suggestions to improve the persuasiveness of the AV messages.

\section{Positive perspectives}

Participants who took a positive perspective found the AV messages were both educating and persuasive. These responses were captured under the two COM-B components of capability and motivation. The theme of capability suggested that the messages influenced participants' knowledge and awareness. The theme of motivation captured perspectives explaining participants' automatic processes of positive emotional reactions as well as reflective processes of self-conscious intentions and evaluation (general likes and dislikes about the messages) of their response.

\section{Capability}

Some participants identified the design team's specifically intended messages, such as that falls happen at all ages and that also that an older person could be active irrespective of the level of their capabilities: 
"I like that you had the walking frame in the dancing, because it sort of shows that it doesn't matter what level of capabilities you've got, you can still be active." (F, L6, Avm3)

Several other participants responded that the AV messages made them aware that they could remain healthy and enjoy life if a fall could be prevented, and that it was important and feasible to stay active at an older age:

"It got the message across straightaway. You get the message, you've got to stay active which helps. To me, I thought it was good." (M, L5, AVm1)

However, several other participants interpreted the AV messages in a concrete and unintended manner, stating that falls could be prevented by eliminating external risk factors or that it was important to adapt to the aging process by moving more carefully and slowly:

"I could see what you're trying to get over, we mustn't turn too quick, things like that, which is what the man could've done. You've got to learn to do that..." (F, L3, AVm2)

Irrespective of whether participants gained intended or unintended messages, several participants felt the AV messages increased their awareness of their aging-related increased falls risk:

"I think when you're growing up and you're doing your daily activities, ... you're in an envelope of your own environment and you know what your parameters are and you don't recalibrate those parameters unless something serious happens to you. So that's probably why people have a serious accident that sort of makes them go: 'whoa hang on, I need to do something about this'. So, it's a good message because it does tell you that there is a steep increase in risk as you get older [...]" (M, L2, AVm1)

The second identified subtheme under the COM-B model component capability was an increased knowledge of falls prevention facts. In particular, the various statistics provided in the messages were compelling to multiple participants.

"I learned some statistics, good. [It] had an intellectual layer. It was educating me." (F, L1, overall comment)

\section{Motivation}


Three subthemes were identified under the motivation theme: positively labeled emotions, reducing aging associated stigma, and personal connection.

Positively labeled emotions expressed were related to being touched by the music and the statistics:

"[The statistics are] alarming and shocking, and that's what you want." (F, L4, overall comment)

Several participants liked the manner in which the different AV messages reduced the aging related stigma associated with falls, for example showing falls as a fact of life during all phases of life or the non-shaming nature of the message:

"It means we're not unique when we get older and falling." (F, L3, overall comment)

"I thought was good about this was that it wasn't shaming. ... I really think that the fact that it wasn't shaming it's more encouragement for people to do something." (F, L4, AVm3)

Several participants expressed a personal connection with the messages, for example because they had a fall themselves or because a message reminded them of their own activities or someone they knew:

"Oh yeah definitely, because I have, you know a parent of that age and a mother-inlaw of that age, ... I mean I guess I'm in the age bracket as well, but I'm considering more my mum.” (F, L6, AVm1)

Other participants said they appreciated, or related to, elements such as the depiction of a family connection, older people being engaged in enjoyable activities, the spoken and/or written messages, the good balance between the imagery and the texts or the gentle approach to the topic:

"It's just a gentle approach to the topic. It didn't just come in blasting all over and it gained your attention ..." (F, L5, AVm2) 


\section{Negative perspectives}

Negative perspectives of other participants were captured under the COM-B components of capability and motivation. These participants found messages non-educating and nonpersuasive in nature.

\section{Capability}

Frequently voiced concerns related to the AV messages lacking ready-to-use falls prevention strategies:

"... because when you are doing the things that we need to be doing for falls prevention, it needs to be targeted exercise, it needs to be bilateral, there needs to be balance and so on..., I don't think they're addressing that issue as much." (F, L4, AVm1)

\section{Motivation}

Three subthemes were identified under the motivation theme: negatively labeled emotions, increasing aging related stigma and lacking personal connection.

A minority of participants, expressing negatively labeled emotions, found some of the videos and the way the message was delivered boring. This may have caused some participants to lose their concentration during the focus group.

"[No, I would not go to the website or call the phone number $]$... Because it was boring." (F, L4, overall comment)

"Not sure whether they were all concentrated on the issue at hand towards the end. [Name] and his wife dozed off at some points during the discussions." (Field note, L5)

Some participants were shocked by the statistics because they left them feeling vulnerable:

"The [statistic about the] large number of people who die from falls [makes me feel] rather vulnerable." (F, L3, AVm2)

One female participant resented the use of the word 'older people' (Table 2). Several other participants' responses also suggested that the implicit messages through either the spoken or visual narratives were perceived as stigmatising for older people: 
"I mean this is designed to encourage people from 55 onward to exercise, that's the point of it. You put them off immediately [because of the use of the word "older people"], I'm quite certain." (F, L3, AVm3)

Several participants' responses suggested they did not feel a personal connection to the messages, especially because they did not feel the topic of falls related to people their age or to them personally:

"If you've had a fall and you're in the age bracket and you've either had a fall or nearly had a fall yes, but if you're not in the age bracket or you don't think that applies to you, why would they bother because it's not meant for this." (M, L2, overall comment)

A lack of personal connection was also expressed by several other participants, who felt the messages were not strong and would not persuade them to go to the recommended website or call the recommended phone number:

"I don't think it's got a very strong message. The whole lot, somehow. No, it really doesn't hit me." (F, L1, overall comment)

\section{Suggestions to improve the message persuasiveness}

The main inductive theme identified from the data pertained to some participants' suggestions to improve the educational and motivational impact of the AV messages as a means to improve the messages' persuasiveness. Several suggestions echoed the participants' perceived lack of ready-to-use falls prevention strategies such as how to get up after a fall or specific exercises:

"Are there say three fabulous exercises that you can do in 30 seconds or whatever that, or something like that that you can actually chuck on the screen?" (F, L4, overall comment)

A considerable number of participants suggested that the messages should contain more drama to attract attention. They suggested that an actual fall was shown because it would make the message more relevant and realistic:

"Get a bit of blood ... It attracts people's attention." (F, L4, overall comment)

"....and you also need to have it realistically: someone falling over the log of wood or the dog or something everyone can relate to." (M, L4, overall comment) 
Using a split-screen approach was mooted during several focus groups as a means to provide the viewer with an alternative to being sedentary or to emphasise the differences between someone who fell and someone who did not fall:

"If, to me, if you could show the result of an accident, even if you had a split screen, this is what happens if you're laid up in hospital. If you had done this, you wouldn't be there. You know, something that's sort of the positive reinforcement ..." (M, L5, Avm2)

Several other suggestions echoed the participants' perceived lack of personal connection with the messages. In particular, participants suggested the messages required tailoring to specific age groups:

"So, the ones you've shown would possibly motivate the over 55 s to, say, the 70 -year olds, but you need a slightly different approach for the over 70s." (F, L3, overall comment)

Finally, a subtheme was identified relating to participants' recommendation not to direct people to online falls prevention information sources, either because they did not use computers or wouldn't go to a website to look for information:

"I think if you are going to try and reach the greatest number of people, a lot of them wouldn't actually go on the website. You'd be better to have it more visual and spoken, on a clip like this." (M, L1, overall comment)

\section{Discussion}

Audio-visual falls prevention messages designed to influence older people's knowledge, awareness and motivation to take action regarding falls prevention elicited a strongly divergent range of reactions among focus group participants. While the presented falls epidemiology statistics) increased some participants' falls risk awareness and falls prevention knowledge, other participants felt ready-to-use falls prevention strategies were lacking. Strong divergence was also evident regarding the overall persuasiveness for the messages, with contrasting positive and negative emotions expressed. The divergent perspectives suggested that participants viewed the messages through different "lenses" (Wurm, Tomasik, \& TeschRömer, 2010). This is explained by findings which suggest that many older people have 
negative views of their own aging, brought about by negative societal perceptions of old age (Kotter-Grühn, 2015). Even though the reference panel members' ideas about the specific messages to be conveyed to their peers were intentionally framed with a positive view of aging in mind, some participants still felt the messages were stigmatising for older people. To analyse the participants' perspectives on the prototype AV messages we applied the COMB (Capability, Opportunity, Motivation to undertake a health Behaviour) model (Michie et al., 2014) to the topic of falls prevention. This model conceptualises that for falls prevention behaviour to occur, the people concerned need the capability (e.g. falls prevention knowledge, awareness- and skills) and motivation (e.g. intentions and desires to take up falls prevention activities). Our results suggest that the focus group participants' falls prevention capability was low, illustrated by the finding that the different falls statistics strongly caught many of the participants' attention and surprised them. Low levels of falls prevention knowledge have been reported previously (Hill et al., 2011; Snodgrass, Rivett, \& Mackenzie, 2005). Several participants felt the AV messages, and especially the compelling epidemiology statistics about falls, increased their awareness of their aging-related increased falls risk. Another important aim of the three developed AV messages was to motivate or persuade the viewer to find out more about how to prevent falls and to engage in enjoyable falls prevention activities. Some studies have suggested that messages that promote activities that enhance health could be more acceptable than advice solely focused on falls prevention (Hughes et al., 2008; Yardley, Donovan-Hall, Francis, \& Todd, 2006). Two of the messages purposely depicted older people being physically active and focused on the fun and social aspects of these activities. However, depicting older people enjoying disco dancing as one example of a healthy and falls preventative activity (Veronese, Maggi, Schofield, \& Stubbs, 2017) was dismissed by several participants who stated that they did not like dancing. Other reasons participants gave for not relating to the message were that they felt the messages were aimed at the wrong (i.e. not their own) age bracket or those who had never had a fall. Previous research has also shown that it is hard to convince older adults that taking up falls prevention strategies will be effective for 
them personally (Haines et al., 2014) and that falls prevention information may be screened out or rejected by some older adults as unnecessary and not personally relevant (Hughes et al., 2008; Yardley et al., 2006), especially if they have not personally experienced a fall (Khong et al., 2016). Personal experience of having had a fall is considered a key influence on an older adult's decision to initiate seeking falls prevention information (Khong et al., 2016). The majority (72\%) of the focus group participants had not experienced a fall in the past 12 months, which may explain why so many participants felt that the messages were not persuasive enough to do something about their falls risk.

It has been suggested that a major public health campaign to raise awareness of health behaviours (Wakefield, Loken, \& Hornik, 2010), such as taking actions to prevent a fall, would help to raise the profile and knowledge of falls (Dickinson et al., 2011). In order for mass media campaigns to be effective, formative research among the target audience should be carried out in the design and/or pretesting of the health messages (Lankford et al., 2014; Wakefield et al., 2010). This approach was used in a previous study (John-Leader et al., 2008), but although older people were involved in fine-tuning the campaign messages, the actual messages were developed by students. In our study a reference panel of older people themselves led the design of the falls prevention messages from inception, but while this resulted seemed to have increased capability, a group of participants were reluctant to take on the implicit actions suggested.

\section{Implications}

The prototype AV falls prevention messages were developed based on what was recommended in the literature combined with input from a reference panel of older people. Several modifications, including diametrically opposing ones, were mooted as a means to make the messages more persuasive. Although the prototype AV messages provided the viewer with concrete directions (Ory, Hoffman, Hawkins, Sanner, \& Mockenhaupt, 2003) about where to find falls prevention information (website, telephone number), several 
participants suggested that providing ready-to-use falls prevention strategies such as exercises and tailoring them to different age groups was important. Especially for people who did not use computers, signposting them to a website may have acted as a barrier to the messages' call to action. Several participants also felt that the AV messages needed to be punchier and more attention grabbing, for example by more explicitly putting "some blood and guts" in them or showing an actual fall. During the development phase of the videos the researchers and reference panel members agreed not to explicitly show a fall based on the notions that falls are a discouraging topic (Clark et al., 2013) and that falling can be viewed negatively and associated with frailty by older people (Dollard, Barton, Newbury, \& Turnbull, 2012;

McInnes, Seers, \& Tutton, 2011). In other health fields it has also been shown that gainframed and loss-framed appeals do not generally differ in persuasiveness (O'Keefe \& $\mathrm{Wu}$, 2012) and that graphic health warnings that elicit strong emotional reactions can be effective in promoting behavioural change (Hammond, 2011). The results of this study suggest that avoiding the f-word (Yardley \& Todd, 2005) may work for some, but clearly not for all older people. The overall variety of responses on the three AV messages confirms that it may be worthwhile providing future falls prevention information in several distinct formats (Khong et al., 2016), using precision health messaging to cater for the divergent variety of people's preferences. For example, different campaign message formats could be used to specifically target both people who have and who have not fallen (Khong et al., 2016) or signpost people both to readily available falls prevention resources and local opportunities as well as providing ready-to-use strategies. Both gentle and more graphic gain-framed and loss-framed messages depicting people of different ages engaged in different activities may be an effective approach, for example by using a split-screen approach as suggested by several participants. Further development of the prototype AV messages as part of a wider falls prevention campaign is currently planned. 
Major strengths of this study are that the AV falls prevention messages were developed and evaluated in collaboration with older people, and that the evaluation was based on the wellestablished COM-B model of behaviour change. The evaluation included older people of different genders and age groups from different urban and rural communities and saturation was also reached by the final focus group. The members of the reference group were agreeable to participate in the panel, were all positive about healthy ageing and supportive of the AV design. The fact that this was not always reflected in the focus groups could indicate that their perspectives may not have reflected those of a broader older population. Although none of the groups were dominated by individual participants we cannot rule out that participants' strong opinions (either positive or negative) may have meant that some more introverted participants were reluctant to directly state their opinion. Participants were well educated, most $(80 \%)$ reported a good to excellent health and a majority $(63 \%)$ reported to having undertaken activities that were aimed at healthy aging or falls prevention. This finding suggests selection bias and may limit the generalisation of the findings.

\section{Conclusions}

AV falls prevention messages designed in collaboration with older people elicited strong divergent (positive and negative) perspectives by their peers regarding the effect of the messages on falls prevention capability and motivation. Participants who expressed positive perspectives suggested that the AV messages were an effective means of raising capability and motivation among older people regarding falls prevention. Participants who expressed negative perspectives suggested that the AV messages would not motivate them to take action regarding falls prevention. Future research should continue to evaluate how to present population level health promotion messages that will appeal to a wide range of older people.

\section{References}

Agency for Healthcare Research and Quality. (2017). Fall Prevention Program 
Implementation Guide. Available online at

https://www.ahrq.gov/professionals/systems/hospital/fallpxtraining/implguide.html

[Accessed 20 March 2018]

Ambrose, A. F., Paul, G., \& Hausdorff, J. M. (2013). Risk factors for falls among older adults: A review of the literature. Maturitas, 75(1), 51-61.

https://doi.org/10.1016/j.maturitas.2013.02.009

Australian Commission on Safety and Quality in Healthcare. (2009). Preventing Falls and Harm From Falls in Older People. Best Practice Guidelines for Australian Hospitals. Available online at http://www.webcitation.org/6x4GEOx7i [Accessed 8 February 2018]

Bergen, G., Stevens, M., \& Burns, E. (2016). Falls and Fall Injuries Among Adults Aged $\geq 65$ Years. Available online at https://www.cdc.gov/mmwr/volumes/65/wr/pdfs/mm6537a2.pdf [Accessed 13 September 2018]. https://doi.org/10.15585/mmwr.mm6537a2

Braun, V., \& Clarke, V. (2013). Succesfull Qualitative Research: A Practical Guide for Beginners (1st ed.). SAGE Publications.

Centers for Disease Control and Prevention. (2017). STEADI - Older Adult Fall Prevention. Available online at https://www.cdc.gov/steadi/ [Accessed 20 March 2018].

Clark, L., Thoreson, S., Goss, C. W., Zimmer, L. M., Marosits, M., \& Diguiseppi, C. (2013). Understanding fall meaning and context in marketing balance classes to older adults. Journal of Applied Gerontology, 32(1), 96-119. https://doi.org/10.1177/0733464811399896

Davidson, P., Halcomb, E., \& Gholizadeh, L. (2013). Focus Groups in Health Research. In P. Liamputtong (Ed.), Research Methods in Health. Foundations for evidence-based practice (2nd ed., pp. 54-71). Oxford University Press.

Dickinson, A., Machen, I., Horton, K., Jain, D., Maddex, T., \& Cove, J. (2011). Fall prevention in the community: what older people say they need. British Journal of Community Nursing, 16(4), 174-180. https://doi.org/10.12968/bjen.2011.16.4.174 
Dollard, J., Barton, C., Newbury, J., \& Turnbull, D. (2012). Falls in old age: A threat to identity. Journal of Clinical Nursing, 21(17-18), 2617-2625. https://doi.org/10.1111/j.1365-2702.2011.03990.x

Dollard, J., Barton, C., Newbury, J., \& Turnbull, D. (2013). Older community-dwelling people's comparative optimism about falling: A population-based telephone survey. Australasian Journal on Ageing, 32(1). https://doi.org/10.1111/j.17416612.2012.00597.x

Dorresteijn, T., Zijlstra, G., Van Eijs, Y., Vlaeyen, J., \& Kempen, G. (2012). Older people’s preferences regarding programme formats for managing concerns about falls. Age and Ageing, 41(4), 474-481. https://doi.org/10.1093/ageing/afs007

Franco, M. R., Tong, A., Howard, K., Sherrington, C., Ferreira, P. H., Pinto, R. Z., \& Ferreira, M. L. (2015). Older people's perspectives on participation in physical activity: A systematic review and thematic synthesis of qualitative literature. British Journal of Sports Medicine, 49(19), 1268-1276. https://doi.org/10.1136/bjsports-2014-094015

Gardiner, S., Glogowska, M., Stoddart, C., Pendlebury, S., Lasserson, D., \& Jackson, D. (2017). Older people's experiences of falling and perceived risk of falls in the community: A narrative synthesis of qualitative research. International Journal of Older People Nursing, 12(4), 1-8. https://doi.org/10.1111/opn.12151

Haines, T., Day, L., Hill, K., Clemson, L., \& Finch, C. (2014). "Better for others than for me": A belief that should shape our efforts to promote participation in falls prevention strategies. Archives of Gerontology and Geriatrics, 59(1), 136-144. https://doi.org/10.1016/j.archger.2014.03.003

Hammond, D. (2011). Health warning messages on tobacco products: A review. Tobacco Control, 20(5), 327-337. https://doi.org/10.1016/j.dhjo.2008.11.001

Hanson, H., Salmoni, A., \& Doyle, P. (2009). Broadening our understanding: Approaching falls as a stigmatizing topic for older adults. Disability and Health Journal, 2(1), 36-44. https://doi.org/10.1016/j.dhjo.2008.11.001 
Hill, A.-M., Hoffmann, T., Beer, C., McPhail, S., Hill, K., Oliver, D., ... Haines, T. P. (2011). Falls after discharge from hospital: Is there a gap between older peoples' knowledge about falls prevention strategies and the research evidence? The Gerontologist, 51(5), 653-662. https://doi.org/10.1093/geront/gnr052

Hughes, K., Van Beurden, E., Eakin, E., Barnett, L., Patterson, E., Backhouse, J., ... Newman, B. (2008). Older persons' perception of risk of falling: Implications for fallprevention campaigns. American Journal of Public Health, 98(2), 351-357. https://doi.org/10.2105/AJPH.2007.115055

Israel, B., Eng, E., Schulz, A., \& Parker, E. (2005). Methods in Community-Based Participatory Research for Health (First). San Francisco.

John-Leader, F., Van Beurden, E., Barnett, L., Hughes, K., Newman, B., Sternberg, J., \& Dietrich, U. (2008). Multimedia campaign on a shoestring: promoting 'Stay Active Stay Independent' among seniors. Health Promotion Journal of Australia, 19(1), 22-28. https://doi.org/10.1071/HE08022

Khong, L. A. M., Berlach, R. G., Hill, K. D., \& Hill, A.-M. (2017). Can peer education improve beliefs, knowledge, motivation and intention to engage in falls prevention amongst community-dwelling older adults? European Journal of Ageing. 14(3), 243255. https://doi.org/10.1007/s10433-016-0408-x

Khong, L., Bulsara, C., Hill, K., \& Hill, A.-M. (2017). How older adults would like falls prevention information delivered: fresh insights from a World Café forum. Ageing and Society, 37(6), 1-18. https://doi.org/10.1017/S0144686X16000192

Kotter-Grühn, D. (2015). Changing Negative Views of Aging: Implications for Intervention and Translational Research. Annual Review of Gerontology and Geriatrics, 35(1), 167186. https://doi.org/10.1891/0198-8794.35.167

Lankford, T., Wallace, J., Brown, D., Soares, J., Epping, J. N., \& Fridinger, F. (2014). Analysis of Physical Activity Mass Media Campaign Design. Journal of Physical Activity and Health, 11(6), 1065-1069. https://doi.org/10.1123/jpah.2012-0303 
Lee, D. C. A., McDermott, F., Hoffmann, T., \& Haines, T. P. (2013). They will tell me if there is a problem: Limited discussion between health professionals, older adults and their caregivers on falls prevention during and after hospitalization. Health Education Research, 28(6), 1051-1066. https://doi.org/10.1093/her/cyt091

McInnes, E., Seers, K., \& Tutton, L. (2011). Older people's views in relation to risk of falling and need for intervention: A meta-ethnography. Journal of Advanced Nursing, 67(12), 2525-2536. https://doi.org/10.1111/j.1365-2648.2011.05707.x

McMahon, S. K., Park, Y. S., Lewis, M. P. H. B., Guan, W., Oakes, J. M., Wyman, J. F., \& Rothman, A. J. (2018). Older Adults ' Utilization of Community Resources Targeting Fall Prevention and Physical Activity. The Gerontologist, 00(00), 1-11. https://doi.org/10.1093/geront/gnx210

Michie, S., Atkins, L., \& West, R. (2014). The Behaviour Change Wheel. A Guide to Designing Interventions. (1st ed.). Great Britain: Silverback Publishing.

O’Keefe, D. J., \& Wu, D. (2012). Gain-framed messages do not motivate sun protection: A meta-analytic review of randomized trials comparing gain-framed and loss-framed appeals for promoting skin cancer prevention. International Journal of Environmental Research and Public Health, 9(6), 2121-2133. https://doi.org/10.3390/ijerph9062121

Ory, M., Hoffman, M. K., Hawkins, M., Sanner, B., \& Mockenhaupt, R. (2003). Challenging aging stereotypes: Strategies for creating a more active society. American Journal of Preventive Medicine, 25(3 SUPPL. 2), 164-171. https://doi.org/10.1016/S0749$\underline{3797(03) 00181-8}$

Polit, D., \& Beck, C. (2014). Essentials of Nursing Research. Appraising Evidence for Nursing Practice (8th ed.). Philadelphia: Wolters Kluwer, Lippincott Williams \& Wilkins.

Smith, M. L., Durrett, N. K., Schneider, E. C., Byers, I. N., Shubert, T. E., Wilson, A. D., ... Ory, M. G. (2018). Examination of sustainability indicators for fall prevention strategies in three states. Evaluation and Program Planning, 68 (February), 194-201. 
https://doi.org/10.1016/j.evalprogplan.2018.02.001

Snodgrass, S. J., Rivett, D. A., \& Mackenzie, L. A. (2005). Perceptions of older people about falls injury prevention and physical activity. Australasian Journal on Ageing, 24(2), 114-118. https://doi.org/10.1111/j.1741-6612.2005.00086.x

Stevens, J. A., Ballesteros, M. F., Mack, K. A., Rudd, R. A., DeCaro, E., \& Adler, G. (2012). Gender differences in seeking care for falls in the aged medicare population. American Journal of Preventive Medicine, 43(1), 59-62.

https://doi.org/10.1016/j.amepre.2012.03.008

Verma, S., Willetts, J., Corns, H., Marucci-Wellman, H., Lombardi, D., \& Courtney, T. (2016). Falls and fall-related injuries among community-dwelling adults in the United States. PLoS ONE, 11(3), 1-14. https://doi.org/10.1371/journal.pone.0150939

Veronese, N., Maggi, S., Schofield, P., \& Stubbs, B. (2017). Dance movement therapy and falls prevention. Maturitas, 102(May), 1-5. https://doi.org/10.1016/j.maturitas.2017.05.004

Wakefield, M. A., Loken, B., \& Hornik, R. C. (2010). Use of mass media campaigns to change health behaviour. The Lancet, 376(9748), 1261-1271. https://doi.org/10.1016/S0140-6736(10)60809-4

World Health Organization. (2007). WHO Global Report on Falls Prevention in Older Age. Available online at http://www.webcitation.org/6rKU08OH9 [Accessed 19 June 2017]. Wurm, S., Tomasik, M. J., \& Tesch-Römer, C. (2010). On the importance of a positive view on ageing for physical exercise among middle-aged and older adults: Cross-sectional and longitudinal findings. Psychology and Health, 25(1), 25-42. https://doi.org/10.1080/08870440802311314

Yardley, L., Donovan-Hall, M., Francis, K., \& Todd, C. (2006). Older people's views of advice about falls prevention: A qualitative study. Health Education Research, 21(4), 508-517. https://doi.org/10.1093/her/cyh077

Yardley, L., \& Todd, C. (2005). Don’t mention the f-word! Available online at 
https://doi.org/10.1016/S0262-4079(07)60618-6 [Accessed 13 June 2018].

Table 1. Characteristics of participants and composition of the focus groups. 
Age, years, mean (range)

Gender, female

Language spoken at home, English

Highest level of education?

Primary education

Secondary education or equivalent

Trade / technical / vocational training

University level qualification

Perceived general health

Poor

Fair

Good

Very good

Excellent

Different types of prescription medication, mean (standard deviation)

Discussed falls prevention with GP or another health professional, yes

Ever undertaken ANY activities that are aimed at healthy aging or preventing falls?, yes

Experienced a fall in the past 12 months?, yes

Injured as a result of the fall?, yes

Focus group details

Location 1: urban area, retirement village, age range 65 to 95

Location 2: urban area, men's shed (males only), age range 64 to 85

Location 3: rural area, retirement village, age range 76 to 87

$10(19)$

Location 4: rural area, community, age range 62 to 94

Location 5: urban area, retirement village, age range 68 to 82

Location 6: urban area, university workplace setting (females only), age range 54 to 63

$2(4)$

Note: all data are frequencies (percentages) unless stated otherwise.

a An Australian men's shed is a community-based, non-profit organisation that is accessible to all men and whose primary activity is the provision of a safe and friendly environment where men are able to work on meaningful projects at their own pace in their own time in the company of other men. A major objective is to advance the well-being and health of their male members. 
Table 2. Participants' opposing perspectives relating to the main themes of capability, motivation and suggestions to improve the persuasiveness of the AV messages.

\section{Theme} Subtheme

Awareness of aging

Capability related falls risk

Knowledge of falls prevention facts

\section{Positive perspectives}

"Well certainly the next time I go to the doctor's I'll be.., I'm talking about it." (M, L2, overall comment)

[The statistics] would [attract my attention] because I had a really nasty

fall last year ... I am really open to as much education as I can get to

help prevent falls in the future." (F, L4, overall comment)

Motivation

Emotions

"Don't laugh now but the music had an effect on me. [because] I'm a

very sentimental person and I was just thinking of lots of accidents that

I've seen in my relatives." (F, L5, AVm2)"

Aging associated "I thought that ["This message was developed for older people. By stigma older people" at the end] was quite good. Yeah. [because] it's when younger people are trying to tell older people what to do, that they can see that as condescending or patronising, whereas if it's coming from their own peers, you know ..." (F, L6, overall comment)

"Very good. Very good, yes, understandable for older people by older people." (M, L2, overall comment)

Personal connection

"Well, I quite related to it because I had a fall in those exact circumstances ..." (F, L3, Avm2)

Negative perspectives

Yeah, but the other thing I would have said was if I was watching that it didn't provide me how... What can I do? ..." (F, L6, AVm1)

"There was no message given for how not to fall." (F, L1, Avm2)

"It's condescending music." (F, L4, Avm1)

"I hated the message at the end. This is for older people, by older people, ... and it was an instant turn-off, ... I think if I saw it on the TV I'd think: 'good for them'." (F, L4, overall comment)

"I mean this is designed to encourage people from 55 onward to exercise, that's the point of it. You put them off immediately [because of the use of the word "older people"], I'm quite certain." (F, L3, overall comment)

"I think you should have more information in there." (M, L1, overall comment)

\section{Suggestions to}

improve

persuasiveness

"If they're going to be like an ad on TV - just bang, hit it. That's about the length it's got to be." (F, L1, overall comment)

"So you could have this bit starting and then you know keep having that for a week and then the following week you can say, well this is what you can do about it, have an active life, do this, do that ... so that it's like a continuing story ... the variety keeps you on message and if one of them doesn't have an impact on a particular then one of the other two might." (F, L6, overall comment) Avm1)

"I think you need to be careful of how many messages you're putting across though.” (F, L6, overall comment)

"I think they should be a bit longer, ... [it] doesn't give us nearly enough about falls and stuff." (F, L1, overall comment)

"People aren't going to be watching these things in sequence. It's best just to have three standalone images that give the same message I reckon.” (M, L2, overall comment)

Note: AVm, audio-visual message; F, female; L, location; $\mathrm{M}$, male. 
Figure 1. Designing audiovisual falls prevention messages with and for older people: "we all look at things different ways".

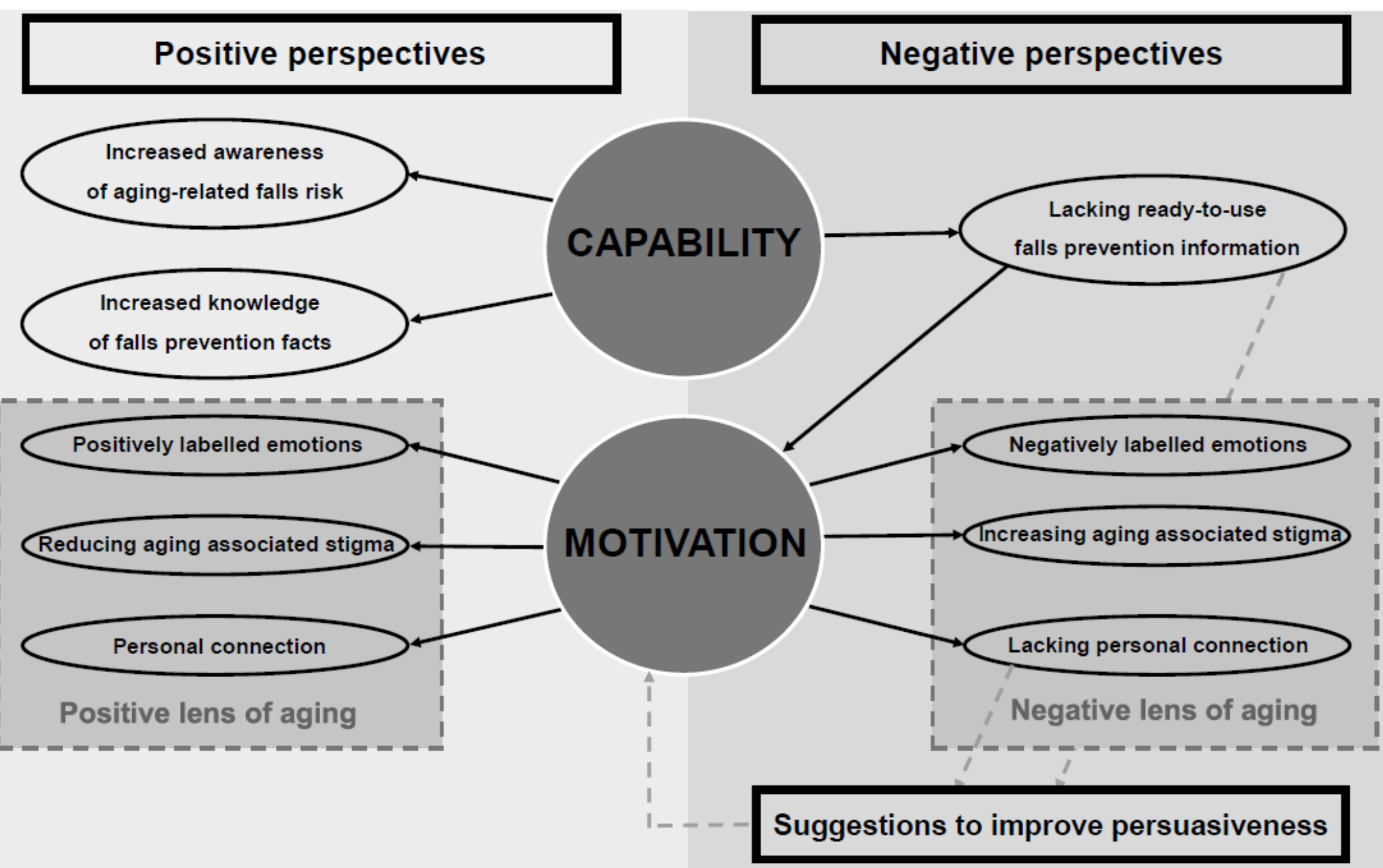




\section{Caption for Figure 1}

Figure 1. Designing audiovisual falls prevention messages with and for older people: "we all look at things different ways". 